\title{
INSIGHTS FROM A MOOC PLATFORM DURING COVID-19 PANDEMIC IN ITALY
}

\author{
Valeria Baudo, Davide Mezzera, Politecnico di Milano - METID, Italy
}

\section{Abstract}

The COVID-19 Pandemic heavily redesigned our lives and our way of teaching and learning. We have witnessed an exponential growth of MOOC enrolment numbers during pandemic as a general world trend, and a big rise in learners in the MOOC platform of Politecnico di Milano. In this paper we will share insights collected from Polimi Open Knowledge during 2020. This analysis enlightens the role of MOOCs for students and citizens during the pandemic, in relation with the specific period of lockdown in Italy.

\section{Introduction - Polimi Open Knowledge}

Polimi Open Knowledge - POK (http://www.pok.polimi.it) is the open knowledge platform of Politecnico di Milano - Polimi, launched in 2014 for the MOOCs delivery. It is based on OpenEdx, an open source learning management system (LMS) developed by MIT and Harvard University to host Massive Open Online Courses (MOOCs). The number of MOOCs and of participants enrolled in POK have steadily grown since its birth. At the time of writing, more than 120,000 enrolled learners can count on 71 MOOCs, provided in Italian or in English (and in some cases in both languages), with up to 2,000 videos and a wide range of educational contents and learning activities.

The underlying philosophy of the platform is to offer educational contents for different target users, according to Collection of courses specifically designed around them:

- MOOCs for students, to improve their knowledge background and their skill set before and during their Bachelor's and Master's degree courses;

- MOOCs for researchers, to help them develop transversal skills, needed for their work;

- MOOCs for professionals, to develop specific technical, hard skills in innovative professional areas and soft skills required by the job market;

- MOOCs for teachers, to support teaching and learning innovation in both Higher Education Institutions and schools; 
- MOOCs for citizens, to explore global challenges and citizenship issues and provide opportunities for lifelong learning not strictly related to career enhancement.

The pandemic has brought back attention to online education in general and especially to MOOCs. The first data (AlQaidoom \& Shah, 2020; Felipe Torres, 2021; Lohr, 2021; Reda \& Kerr, 2020; Shah, 2020) shows an increasing trend for all major MOOC providers. In March 2020 data shows a big rise in the number of learners visiting POK. During 2020 registered users increased by $28 \%(+24,890$ new learners) compared to a $25 \%$ growth $(+17,412$ new learners) in 2019. The total number of registered users at the end of 2020 was 113,108. POK users can be divided into two main clusters: firstly, Polimi users that include all people registered with an institutional account of Politecnico di Milano (most of them are students, but there are also teaching and administrative staff, researchers, alumni, etc.) and secondly external users, such as students from other institutions, teachers from high schools and, generally speaking, all people willing to learn new things or strengthen their knowledge around specific subjects. POK offers the same services to both groups: users have the same chance to access the courses, and to obtain certificates of participation; thus, the use patterns of the platform are somehow comparable between the two groups.

Looking at the series of data collected along POK history, it is evident an increase in the number of daily active users during specific periods of the year (we define "active user" a person who logs into the platform performing an action in a course, on a specific day). Most user activities generally occur in February and in September, concurrently with the start of the first and the second semester, which is an indicator of the integration of MOOCs into curricular activities. During 2020 the above-mentioned periods in February and in September show the usual increase of the activities on the platform, but there is a third, unexpected peak during April 2020; it is possible to notice how this trend is directly related to the situation of total lockdown in Italy.

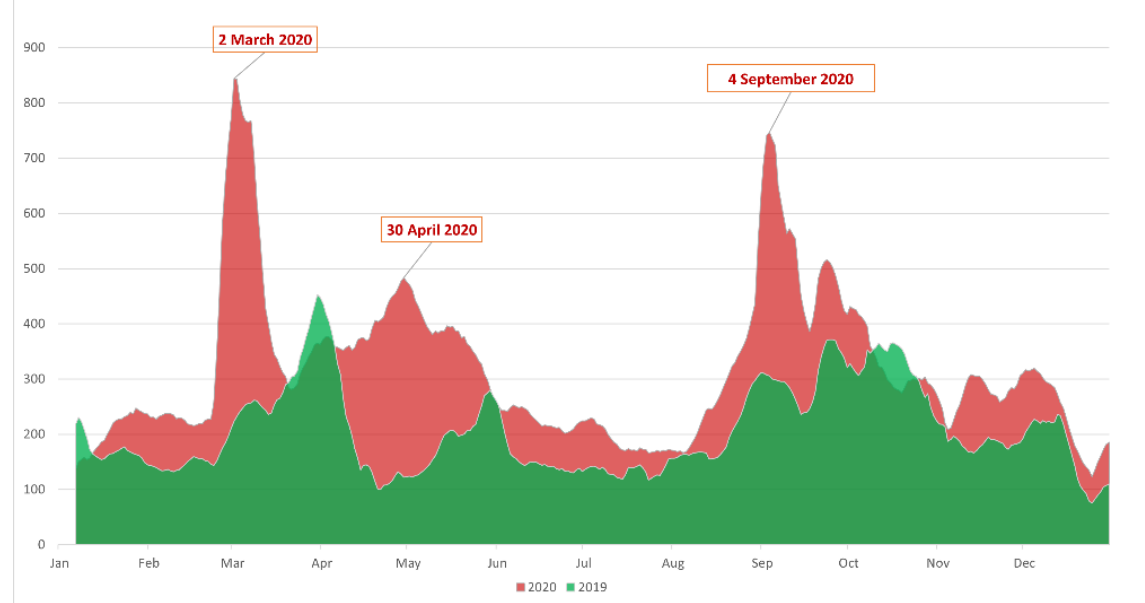

Figure 8. Daily active users on POK: trends of 2019 vs 2020 - 7-day moving average 


\section{MOOCs for didactics during lockdown}

On the $17^{\text {th }}$ of February 2020 the first Italian cases of COVID-19 were detected in Lombardy, the region where Politecnico di Milano is located. It was something dramatically unexpected, and the university moved its teaching and learning activities totally online in a couple of weeks. The already existing practices of blended learning and flipped classroom, together with the technological solutions provided, made it possible to quickly shift to the fully online mode. In this scenario, MOOCs played a crucial role in supporting and even steering this transformation: Politecnico di Milano was the Italian university that responded sooner and faster to the demanding requirements of social distancing. At the beginning of March all schools - from kindergarten to university - were closed by law, and on the 9th of March the lockdown was officially enacted.

In this emergency scenario, MOOCs arose as a key resource to shift didactic activities online (Kichu \& Bhattacharya 2021; Sun, 2020). Integrating and making the most of MOOCs in didactics is one of the several missions of METID, the learning and teaching innovation task force of Politecnico di Milano. METID designs and develops MOOCs and it is in charge of faculty training. Even before the pandemic, MOOCs have been specifically designed to support teaching and learning innovation, blended learning processes and flipped classroom approaches. There are currently more than 150 Polimi courses that officially integrate MOOCs into teaching and learning experiences, and the pandemic disrupted this trend as an easy way to shift to the fully online scenario.

Although we usually experience a peak at the beginning of each semester, during 2020 the numbers were higher than ever. Having a look at the learners' profiles during the first four weeks of the second semester, we notice that more than $60 \%$ of active users are from Politecnico di Milano (compared to an average of $37 \%$ of institutional users generally in the platform). In addition to that, in the past years some of the MOOCs specifically created for students, were used in teaching, but in 2020 data showed a different model, with MOOCs being used in a shorter period of time, instead of a widespread use during the whole semester, attesting that MOOC were a lever for the fully online scenario.

This is evident in analysed data because there are more than 800 daily active users on average in the first week of March, while in the previous years learners participated in MOOCs in distributed periods of the year. Having a set of MOOCs already available, and in many cases designed in consistency with curricular learning outcomes, these online courses suddenly became a key strategic resource to face the emergency created by the pandemic and allowed the university to promptly respond with a ready-to-use alternative to face-to-face didactics. It is needless to add that they didn't replace classroom experiences 
completely, but adapting to the emergency was definitely easier, and the level of offering was largely higher than what would have been with no MOOC available.

This trend is evident in the MOOC "Equazioni differenziali lineari del secondo ordine", used in courses such as Mathematical Analysis and Differential Equations. During COVID pandemic teaching staff took advantage of the MOOC as an asset for online didactics, requiring students to use it. In Figure 2 it is possible to notice the difference in the behaviour of active users between 2019 and 2020. In 2020 active users were more numerous, and the actions performed by them are concentrated in time, according to the model of use of MOOC as a key asset in the first phase of the lockdown.

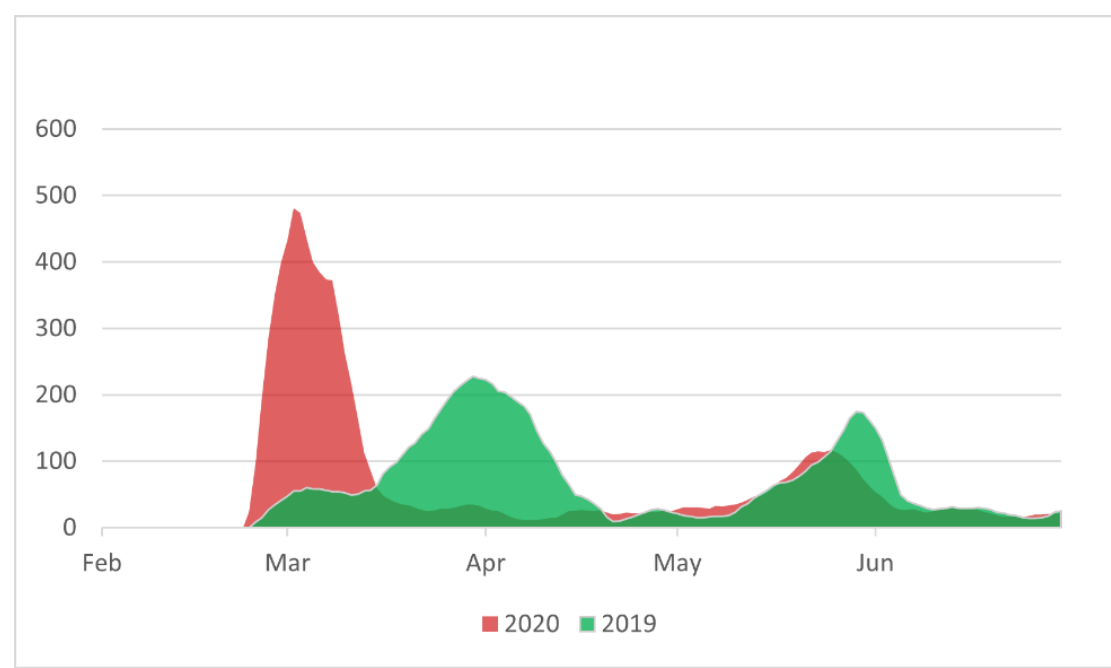

Figure 2. Active users of "Equazioni differenziali lineari del secondo ordine" in 2019 and 2020 - 7day moving average

\section{MOOCs for citizens during lockdown}

Starting from the $22^{\text {nd }}$ of March 2020, the lockdown in Italy imposed a complete restriction of movement and gathering nationwide, and a total closure of economic activities except for essential services. Everyone, except essential workers, had to stay at home.

Looking at the insights from POK, data showed an unexpected side effect of the confinement. People, once locked down, were keen to take advantage of their compulsory "free time" to strengthen their skills and to gain new knowledge through MOOCs. In the graph below the line referring to external users has a peak in the period of April-May. This trend is totally new for the platform and it is related to the specific contingency. 


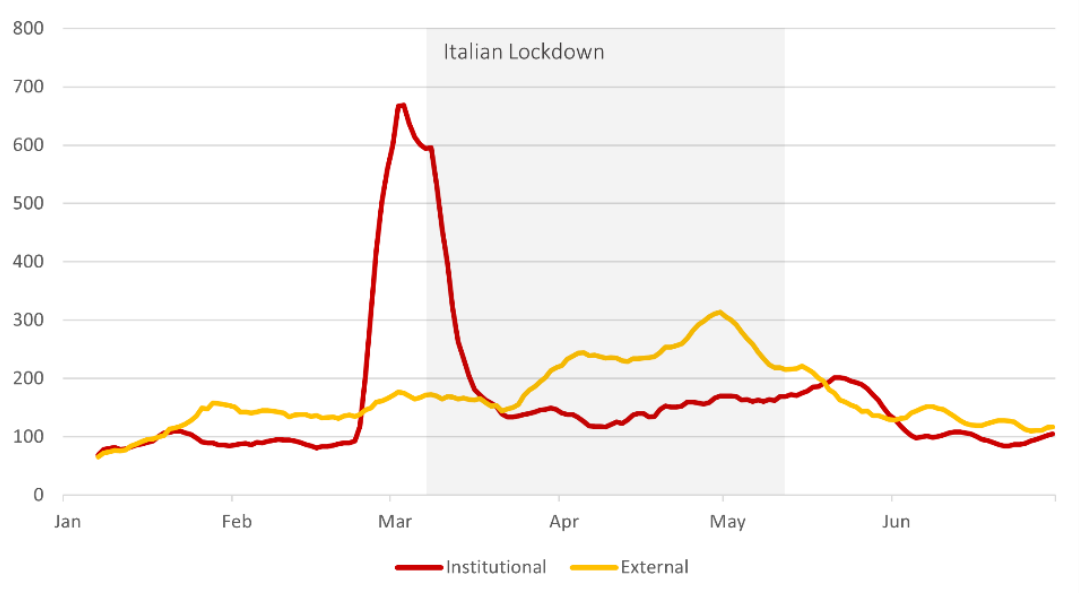

Figure 3. Institutional and external active users during the lockdown - 7-day moving average

The analysis of the most popular courses among external users during April-May 2020 revealed that the most appreciated are basically related to soft skills and personal development (such as "Gestione del Conflitto/Managing Conflicts", "Gestione del cambiamento/Managing Changes") and "Finanza per Tutti", a "MOOC for citizens" on financial education. Looking deeper at the profile of participants, they are basically Italian (it is not surprising since these MOOCs are taught in Italian) and in the age range 35-50 years, the majority of them being in the labour market with no specific distinction related to gender.

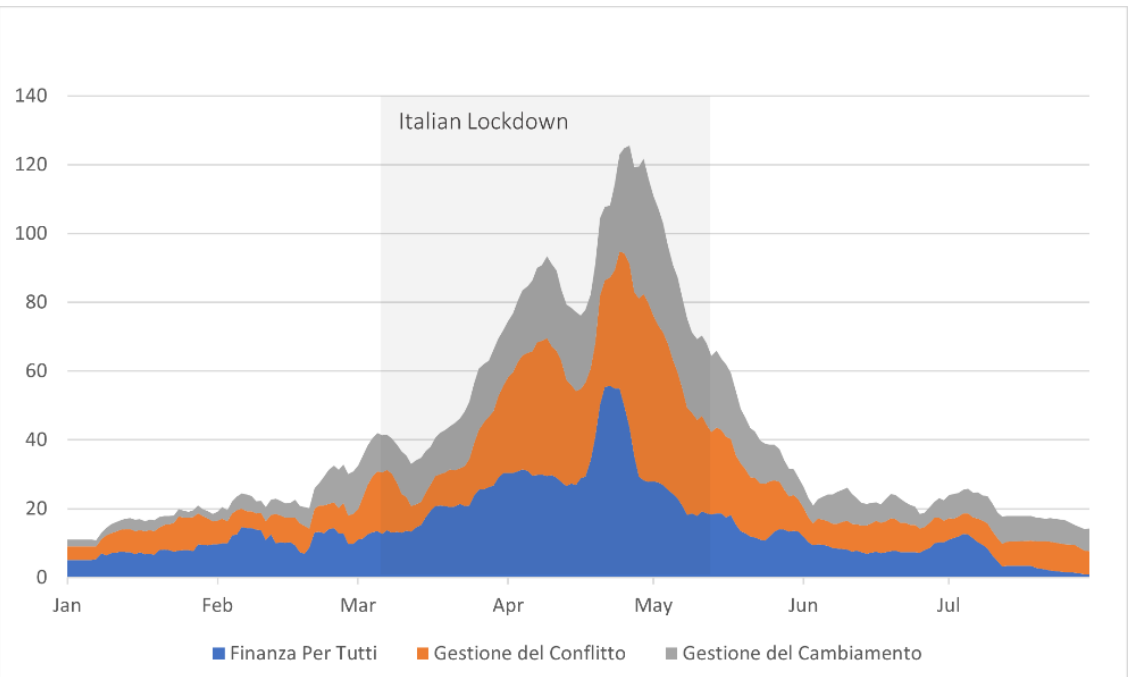

Figure 4. The cumulative increase of no-institutional active users in the most popular MOOC during lockdown

\section{The use of MOOC in HyFlex Classroom setting}

In the last period of the year, right after summer, the situation changed again. The second wave of COVID-19 reached Italy in autumn. A new lockdown was decided, with small differences from the previous one of March 2020. More people were allowed to go to work 
(although remote working was highly encouraged), more commercial activities were open with limitations, some schools reopened, and universities were allowed to teach partially in presence in compliance with social distancing norms.

This situation had consequences also in the data from the platform: in fact, the most active users were the institutional ones. The classes in Higher Education started following a hybrid model, combining face to face presence (for people willing/able to do so) and remote teaching. The so-called HyFlex classroom, in Italian called "classe estesa", is the way that universities are using to face restrictions due to the pandemic. This model combines instructors teaching students in a physical classroom and - at the same time - students participating online via video-conferencing software. In some experimentations, teachers themselves are online and students go physically to class. It is an interesting model that requires an accurate design of the teaching and learning experience (Beatty, 2019; Cohen, Nørgård, \& Mor, 2020; Hodges, Moore, Lockee, Trust, \& Bond, 2020; Irvine, 2020)

Online resources and MOOCs play a crucial role in this setting. Although we still lack a set of data about it, since it is still an ongoing experience, it is possible to offer insights from a MOOC that has been integrated in didactics following a different approach in teaching in September 2020. The course is "Introduzione alla Matematica per l'università: Precalculus" and it is offered to our first-year students to deepen or review some basic mathematical concepts. The MOOC is part of Polimi refresher courses that are generally offered in presence but moved online in 2020: the integration with the MOOC changed, shifting from a flipped classroom approach to a virtual flipped approach.

This course does not specifically represent the model of HyFlex courses, but it can be used as a "litmus test" and can give ideas about future trends.

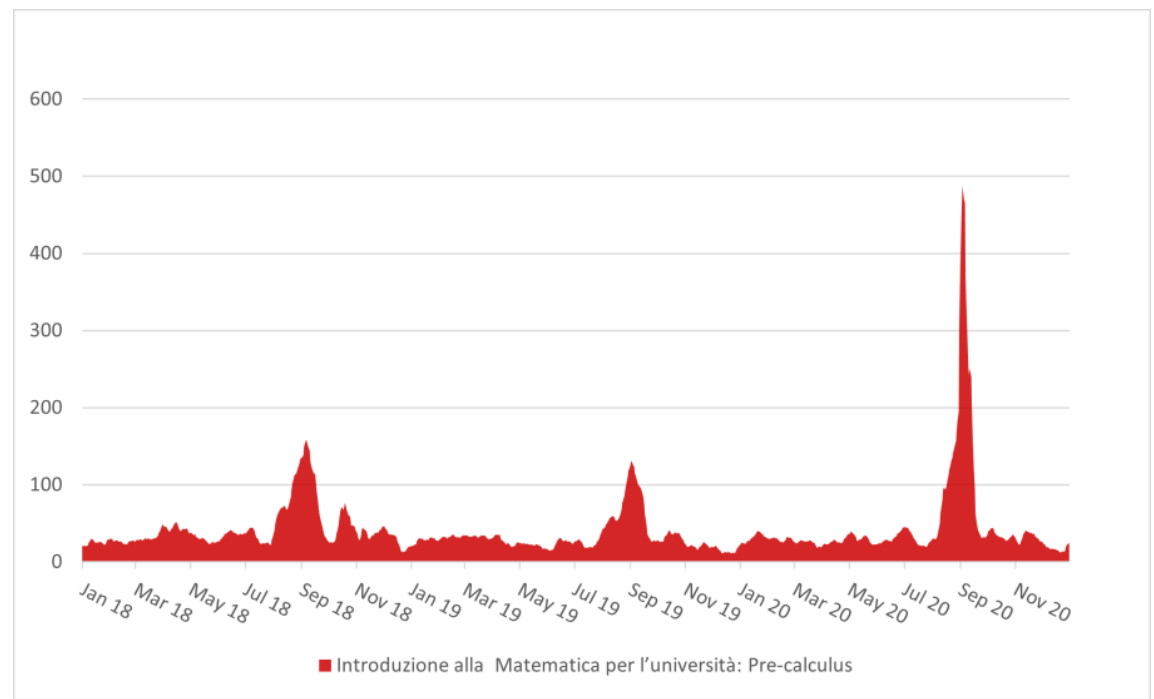

Figure 5. Active users in "Introduzione alla matematica per l'Università" from 2018 to 2020 - 7-day moving average 
The number of active users in "Introduzione alla Matematica per l'università: Precalculus" MOOC in September 2020 reached impressive numbers, increasing by $400 \%$ the active users in specific days. The newly adopted model integrates a strong schedule for MOOC participation, less free than it usually is in the "traditional" flipped classroom approach. Learners are requested to show up online in the MOOC, according to specific timing in specific days; they watch listed videos, then do the quizzes; then they move back to the online virtual classroom in Microsoft Teams and meet the teachers, they can ask them questions to solve their doubts regarding contents and exercises; finally, they come back to the MOOC and post in the forum the results of their exercises. Teachers themselves have been positively impressed by the results of this learning path and noticed a growing sense of comfort and familiarity of first-year students with online teaching and learning and, more in general, with MOOCs. Although it is not possible to empirically provide evidence so far, this might be related with these students' previous experience in online didactics (in Italian "Didattica a Distanza”, DAD) at the end of their high school learning path, due to the pandemic.

\section{Conclusion and limits}

However, the main caveat of this paper is that pandemic is still ongoing, and it is not possible to infer that the insights shown are a new trend or a unicum due to current contingencies. Although some studies recently published stressed the importance of the MOOC in the so-called "new normal" in higher education, not enough data and literature have been published so far to confirm that.

This study is limited to one University and one MOOC platform, while a combination of studies on different universities and on different platforms can provide a more complete picture. Furthermore, this analysis can be fruitfully integrated with a qualitative approach, in order to give back a more complete overview.

Despite these limits, the data shown in the paper highlighted the important role of MOOCs for higher education institutions and for citizens during the pandemic. 


\section{References}

AlQaidoom, H., Shah, A., (2020). The Role of MOOC in Higher Education during Coronavirus Pandemic: A Systematic Review. International Journal of English and Education, 9(4).

Beatty, B. J. (2019). Hybrid-flexible course design. Implementing student directed hybrid classes. Provo, Utah: EdTech Books. https://edtechbooks.org/hyflex

Cohen, A., Nørgård, R. T., \& Mor, Y. (2020). Hybrid learning spaces--Design, data, didactics. British Journal of Educational Technology, 51(4), 1039-1044. https://doi.org/10.1111/bjet.12964

Eradze, M. et al. (2020). Hybrid Flexible Learning with MOOCs: A Proposal to Reconceptualize the COVID19 Emergency beyond the Crisis. IEEE Learning with MOOCS, 174-179.

Farnell, T., Skledar Matijević, A., \& Šćukanec Schmidt, N. (2021). The impact of COVID19 on higher education: a review of emerging evidence. NESET report, Luxembourg: Publications Office of the European Union. doi: 10.2766/069216.

Felipe Torres, G, (2021, March 18). Boosted by the Pandemic, MOOCs Are Here to Stay. How Can We Improve Them? Elearning Insight [Blog post]. Retrieved from https://news.elearninginside.com/boosted-by-the-pandemic-moocs-are-here-to-stayhow-can-we-improve-them/

Hodges, C., Moore, S., Lockee, B., Trust, T., \& Bond, A. (2020, March 27). The Difference between Emergency Remote Teaching and Online Learning. EduCause [Blog post]. Retrieved from https://er.educause.edu/articles/2020/3/the-difference-betweenemergency-remote-teaching-and-online-learning

Irvine, V. (2020, October 26). The Landscape of Merging Modalities, EDUCAUSE [Blog post]. Retrieved from https://er.educause.edu/articles/2020/10/the-landscape-ofmerging-modalities

Kichu, M., \& Bhattacharya, M. (2021). COVID-19 Pandemic impels surge in MOOC learning and the New Normal: A Literature Review. IJIRT.

Li, C., \& Lalani, F. (2020). The COVID-19 pandemic has changed education forever. This is how. World economic forum, 29. Retrieved from https://www.weforum.org/agenda/2020/04/coronavirus-education-global-covid19online-digital-learning/

Lohr, S. (2021, May 26) Remember the MOOCs? After Near-Death, They're Booming. The New York Times [Blog post]. Retrieved from https://www.nytimes.com/2020/05/26/technology/moocs-online-learning.html 
Reda, V., \& Kerr, R. (2020, March 31). Moocs have helped Italy keep teaching during the pandemic. The World University Rankings [Blog post]. Retrieved from https://www.timeshighereducation.com/blog/moocs-have-helped-italy-keepteaching-during-pandemic

Shah, D. (2020, December 23). The Second Year of The MOOC: 2020 Saw a Rush to Large-Scale Online Courses. EdSurge [Blog post]. Retrieved from https://www.edsurge.com/news/2020-12-23-the-second-year-of-the-mooc-2020-sawa-rush-to-large-scale-online-courses

Sun, Y. (2020). Reflection on MOOCs in the Special Period of Anti-coronavirus. Theory \& Practice in Language Studies. doi: 10.17507/tpls.1011.23 